\title{
Welfare Implications of Alternative Monetary Policy Rules: A New Keynesian DSGE Model for Turkey Özge Filiz Yağcıbaşı, ${ }^{1}$ Mustafa Ozan Yıldırım²
}

\begin{abstract}
In recent years, there has been extensive research on the conduct of monetary policy in small open economies that are subject to inflation and output fluctuations. Policymakers should decide whether to implement strict inflation targeting or to respond to the changes in output fluctuations while conducting monetary policy rule. This study aims to examine the response of alternative monetary policy rules to Turkish economy by means of a DSGE model that is subject to demand and technology shocks. The New Keynesian model we used is borrowed from Gali (2015) and calibrated for the Turkish economy. Welfare effects of alternative Taylor rules are evaluated under different specifications of central bank loss function. One of the main findings of this paper is that in the case of a technology shock, strict inflation targeting rules provide the minimum welfare loss under all loss function configurations. On the contrary, the losses are weakened if the monetary authority responds to output fluctuations in the presence of a demand shock. Finally, there exists a trade-off between the volatility of output and inflation in case of a technology shock, while the volatility of both variables moves in the same direction in response to a demand shock.
\end{abstract}

Keywords: Central Bank, DSGE, Monetary Policy, Taylor Rule

JEL Classification: E52, E58, E12

Received: 9 May 2017 / Accepted: 9 October 2017 / Sent for Publication: 8 December 2017

\section{Introduction}

After the abandonment of the fixed exchange rate system, increasing number of countries started to adopt the inflation targeting (IT) regime to as their monetary policy framework. This regime provides a more transparent and coherent central bank and proved to be very successful in stabilizing inflation. Simple instrument rules of Taylor type prove to be useful both academically and practically in this environment.

After the severe hit of 2001 crisis, The Central Bank of Republic of Turkey (CBRT) has gained its formal independence with the new central bank law on May 25, 2001. The

\footnotetext{
${ }^{1}$ Department of Economics, Katip Çelebi University, İzmir, Turkey

${ }^{2}$ Department of Economics, Pamukkale University, Denizli, Turkey. Corresponding Author: moyildirim@pau.edu.tr
}

(C) 2017 by the authors; licensee Review of Economic Perspectives / Národohospodářský obzor, Masaryk University, Faculty of Economics and Administration, Brno, Czech Republic. This article is an open access article distributed under the terms and conditions of the Creative Commons Attribution 3.0 license, Attribution - Non Commercial - No Derivatives. 
newly adopted monetary policy was characterized by flexible exchange rates and inflation targeting regime. Price stability was declared to be the primary objective of the CBRT. The determination of the appropriate monetary policy for countries that have been exposed to high inflation for a long time, such as Turkey, has an indisputable significance for macroeconomic stability. In a broad sense, there are many papers related to the monetary policy reaction function and Taylor rule in the era of inflation targeting by using different econometric approach as DSGE models. Gürkaynak et al. (2015) argue that there exists a structural break in monetary policy conduction in the year 2009, while pre-2009 rules are strongly responsive for controlling inflation, post-2010 rules are weak in the sense that they do not react to rising inflation. ${ }^{3}$ Özatay (2011) states that the Turkish economy has begun implementing a new monetary policy aimed at providing financial stability since 2010. The number of studies on Taylor Rule and monetary policy reaction function related to the Turkish economy has been increasing in the last decade. Aklan and Nargelecekenler (2008) estimate the backward-looking reaction function of the CBRT from 2001 to 2008. Their findings reveal that inflation rate, output gap, and exchange rate are the key variables which CBRT reacts to and the primary target is the price stability.However, there are also some studies in the literature that have contrary findings. Berument and Taşçı (2004) show that between 1990 and 2000, the primary target of CBRT was national output rather than inflation. Pehlivanoğlu (2014) finds that over the period 1987-2013 the monetary authority has paid more attention to the variations in output as a major goal than to price stability. Furthermore, Uslu and Özçam (2014) also state that the real GDP growth is the main consideration in conducting monetary policy in the scope of Taylor rule especially after 2012. Güney (2016) provides evidence about Taylor rule that investigates the effects of uncertainty regarding monetary policy implementation in Turkey. His finding is that inflation and output growth uncertainties are significantly important for CBRT's reaction function in addition to price stability. Bulut (2017) investigates the reaction of the Central Bank to fluctuations in asset prices after the global crisis in Turkey. His findings show that while the stock market index gap has been found statistically insignificant, exchange rate gap have significant contributions on the interest rate adjustments. Yüksel et al. (2013) analyze the Taylor-type monetary policy rule with a time-varying parameter (TVP) approach by employing a structural extended Kalman filter (EKF). Their results reveal that the EKF performs better than the standard Kalman filter in estimating the reaction function of the central bank. Özçelebi et. al. (2014) seek the effects of both domestic and foreign variables on short-term interest rates in the context of Taylor rule. Their findings reveal that the technology shocks are important determinants in the designation of short-term interest rates as well as foreign output, domestic inflation, and terms-oftrade.

Although there are many different econometric approaches applied by many researchers, in recent years, the evolution of the New Keynesian Dynamic Stochastic General Equilibrium (DSGE) models with imperfect competition and nominal stickiness have become standard and dominant tools in central banks and for policymakers in the analysis

${ }^{3}$ Gürkaynak et al. (2015) 
of the relationship between monetary policy and macroeconomic variables (Christiano et al., 2005; Smets and Wouters, 2007). The use of the DSGE models has drawn attention in the developed and developing countries over the last decade (Adolfson et al, 2014; Clarida, 2014; Curdia and Finocchiaro, 2013; Patra et al, 2017). Bouda (2015) studies the influence of alternative monetary policy rule that a monetary policy shock is expressed as a New Keynesian Model (NKM) on the Czech Republic. He attempts to test the appropriateness of different Taylor rules that the central bank follows. His results show that while the variation of GDP results from exogenous shocks, technology shocks account for a negligible part of GDP. He also points that forward-looking monetary policy rules explain the facts much better than the simple and other alternative monetary policy rules that are used in the paper. Gambacorta and Signoretti (2014) evaluate the Taylor rule augmented with asset prices by comparing it with standard Taylor rule both in terms of macroeconomic stabilization and individual's welfare in a DSGE model. Their findings indicate that even in a model where financial stability is not considered as an explicit policy goal, countercyclical monetary policies are suitable against supply-side shocks.

Even though there is a sufficiently large body of the literature on DSGE models, estimated DSGE models for Turkey that focus on the use of Taylor rule are both very new and limited in number. Çebi (2011) examines the interaction between monetary and fiscal policy by using an estimated New Keynesian DSGE model. The results suggest that the response of the monetary authority to output gap shocks are weak. His results show that the fiscal policy makes an important contribution to the debt stabilization. Alp and Elekdağ (2011) analyze how large the effects of the financial crisis might have been if the inflation targeting regime augmented with the flexible exchange regime was not implemented. Their findings indicate that both the interest rate policy and the flexible exchange rate system lessen the effects of the financial crisis. Bari and Ş1klar (2016) use a small open economy DSGE model with nominal and real rigidities, imperfect competition, and habit formation in the consumer's utility function. Their results reveal that monetary authority responds strongly to inflation shocks but it responds weakly to the output gap. Sekmen and Şıklar (2016) estimated a DSGE model that considered a macroprudential policy tool. Their findings show that the reaction of monetary policy to credit expansions and the use of macro-prudential policies enhances the macroeconomic stability under different economic conditions.

The present study employs a New-Keynesian DSGE model borrowed from Gali (2015) to evaluate the use of alternative monetary policy rules by the Central Bank of Republic of Turkey. Although this is a simple (textbook) model, it allows us to study the welfare implications of alternative monetary policy rules sufficiently well. There may be many extensions which may improve the findings and make the model economy more realistic. However, our focus is monetary policy and this form would be very useful to understand the underlying basic dynamics of monetary policy. This model and monetary policy rules are simple, tractable, policy-oriented, and compatible with macroeconometric models and fit the data. In order to tailor the model to the Turkish economy, we calibrated the key parameters such as Calvo parameter, Taylor rule coefficients and the interest rate smoothing parameter accordingly. 
For this purpose, several simulations are applied in the framework of the Turkish economy. Initially, the parameters in the Taylor rule are altered to evaluate the welfare losses under different conditions that comprise the anti-inflationary and/or output gap stabilization stance respectively by using the loss function defined in Gali (2015). Then the loss function specification is modified to observe whether the alternative loss function configurations would provide different results. Secondly, inflation sensitivity is kept constant and only the output gap sensitivity is allowed to change. Finally, the scenario in which both inflation and output gap sensitivity are allowed to alter is discussed.

One of the main findings of this paper is that in the case of a technology shock, strict inflation targeting rules provide the minimum welfare loss under all loss function configurations. On the contrary, the losses are weakened if the monetary authority responds to output fluctuations in the presence of a demand shock. Finally, there exists a trade-off between the volatility of output and inflation in the case of a technology shock, while both variables' volatility moves in the same direction in response to a demand shock. The key contribution of this study to literature is that it analyzes the effects of the practice of alternative Taylor rules and loss functions in the context of a DSGE model calibrated for the Turkish economy.

The remainder of the paper is as follows. Section 2 presents the theoretical model used in the present paper. Section 3 details the calibration. In section 4 simulation procedure and results are reported. Finally, conclusions are presented in the last section.

\section{Model}

The model used in the present paper is a simplified version of the model developed by Gali (2015). The structure of the model is a standard New Keynesian DSGE model of a closed economy that is characterized by imperfect competition, and Calvo-type price formation. New Keynesian models differ from classical monetary models in the sense that there exist nominal rigidities (in prices, wages or both) and imperfect market structures. These departures make way for monetary policy to be effective in the short run. The model we use is one of the most basic New Keynesian frameworks and closely follows the solution path of Gali (2015). Since the business cycle capital stock and output have a relatively weak relation, the basic New Keynesian model does not take capital stock into consideration. But as we will see, the model is effective enough to capture the dynamics of the economy.

The model consists of three types of agents: households maximize their utility subject to their budget constraint, firms produce differentiated goods by using only labor and the Central Bank follows Taylor-type interest rate rule to set nominal interest rate. Problems of each specific sector will be discussed in following subsections.

\section{Households}

A representative infinitely-lived household attains utility from consumption and leisure and maximizes the following utility function: 


$$
E_{0} \sum_{t=0}^{\infty} \beta^{t} U\left(C_{t}, N_{t} ; Z_{t}\right)
$$

where $E_{t}$ denotes the mathematical expectations operator conditional on information available at time t, $N_{t}$ denotes hours worked, $\beta \in(0,1)$ is the discount factor and, $C_{t}$ is the composite consumption index given by a CES index of individual consumption goods.

Conditional on optimal behaviour households' budget constraint takes the following form:

$$
P_{t} C_{t}+Q_{t} B_{t} \leq B_{t-1}+W_{t} N_{t}+D_{t}
$$

where $W_{t}$ is the nominal wage, $B_{t}$ denotes purchases of one-period discount bonds, $Q_{t}$ is the price of the bonds and $D_{t}$ represents dividends from the ownership of the firms.

It is assumed that the household's utility is given by

$$
U\left(C_{t}, N_{t} ; Z_{t}\right)= \begin{cases}\left(\frac{C_{t}^{1-\sigma}-1}{1-\sigma}-\frac{N_{t}^{1+\varphi}}{1+\varphi}\right) Z_{\mathrm{t}} & \text { for } \sigma \neq 1 \\ \left(\log \left(C_{t}\right)-\frac{N_{t}^{1+\varphi}}{1+\varphi}\right) Z_{t} & \text { for } \sigma=1\end{cases}
$$

where $\sigma$ denotes the intertemporal elasticity of substitution, $\varphi$ is the inverse (Frisch) labor supply elasticity, and, $z_{t}=\log \left(Z_{t}\right)$ follows an exogenous AR (1) process $z_{t}=\rho_{z} z_{t-1}+\varepsilon_{t}^{z}$ with $\rho_{z} \in[0,1)$ and $\varepsilon_{t}^{z} \sim i i d$.

Log-linear versions of the optimality conditions associated with households' maximization problem are given by

$$
\begin{gathered}
w_{t}-p_{t}=\sigma c_{t}+\varphi n_{t} \\
c_{t}=E_{t}\left\langle c_{t+1}\right\rangle-\frac{1}{\sigma}\left(i_{t}-E_{t}\left\langle\pi_{t+1}\right\rangle-\rho\right)+\frac{1}{\sigma}\left(1-\rho_{z}\right) z_{t}
\end{gathered}
$$

where $i_{t}=-\log \left(Q_{t}\right)$ represents the short-term nominal interest rate and $\rho=-\log (\beta)$ is the discount rate. Finally, money demand equation of the household is given by

$$
m_{t}-p_{t}=y_{t}-\eta i_{t}
$$

where $m_{t}$ represents nominal money holdings. Following the common use, we use lowercase letters to denote the logs of the original variables.

\section{Firms and Price Setting}

There is a continuum of monopolistic ally competitive domestic firms, indexed by $i \epsilon[0,1]$. Each firm produces a differentiated good using only labor as an input. All firms are assumed to use identical technology. The production function is given by 


$$
Y_{t}(i)=A_{t} N_{t}(i)^{1-\alpha}
$$

where $A_{t}$ denotes the level of technology. Technology evolves exogenously over time according to the following process

$$
a_{t}=\rho_{a} a_{t-1}+\varepsilon_{t}^{a}
$$

with $\rho_{a} \epsilon[0,1]$ and $\left\{\varepsilon_{t}^{a}\right\}$ is a zero mean white noise process. Demand for good i is characterized by optimization of household and given by equation (1) where aggregate price level and consumption index is given.

As in Calvo (1983), at each period only a measure of $1-\theta$ of producers can change their prices. Remaining $\theta$ portion of producers keep their prices unchanged. Aggregate price dynamics can be characterized by

$$
\pi_{t}^{1-\epsilon}=\theta+(1-\theta)\left(\frac{P_{t}^{*}}{P_{t-1}}\right)^{1-\epsilon}
$$

where $\pi_{t} \equiv \frac{P_{t}}{P_{t-1}}$ is the gross inflation between $\mathrm{t}-1$ and $\mathrm{t}$, and $P_{t}^{*}$ is the price derived from the reoptimizing agents. Since all firms have access to the same production technology, the reoptimizing price level is symmetric among the producers who can reset their prices. Log linear approximation around zero inflation steady state is given by

$$
p_{t}=\theta p_{t-1}+(1-\theta) p_{t}^{*}
$$

Optimal price for the producers who can reset their prices is determined by solving the firm's optimization problem. Firms maximize their current market value of the profits

$$
\max _{P_{t}^{*}} \sum_{k=0}^{\infty} \theta^{k} E_{t}\left\{\Lambda_{t, t+k}\left(1 / P_{t+k}\right)\left(P_{t}^{*} Y_{t+k \mid t}-C_{t+k}\left(Y_{t+k \mid t}\right)\right)\right\}
$$

subject to the sequence of demand constraints

$$
Y_{t+k \mid t}=\left(\frac{P_{t}^{*}}{P_{t+k}}\right)^{-\epsilon} C_{t+k}
$$

where $C_{t}$ is the nominal cost function, $Y_{t+k \mid t}$ represents output in period $t+\mathrm{k}$ for a firm that last reset its price at period $\mathrm{t}$ and $\Lambda_{t, t+k}$ is the stochastic discount factor. Applying first order Taylor approximation around zero inflation steady state to the optimality condition associated with the above problem yields

$$
p_{t}^{*}=\mu+(1-\beta \theta) \sum_{k=0}^{\infty}(\beta \theta)^{k} E_{t}\left\{\psi_{t+k \mid t}\right\}
$$

where $\psi_{t+k \mid t} \equiv \log \Psi_{t+k \mid t}$ denotes the marginal cost and $\mu$ is the desired gross markup. Hence, the optimizing price level is forward looking in the sense that the combination of desired mark up and the weighted average of current and expected marginal cost. 


\section{Central Bank}

The Central bank is assumed to follow a simple interest rate rule of the Taylor type:

$$
i_{t}=\rho+\gamma i_{t-1}+\phi_{\pi} \pi_{t}+\phi_{y} \tilde{y}_{t}+v_{t}^{4}
$$

$v_{t}$ denotes the exogenous monetary policy shock that evolves according to the following process:

$$
v_{t}=\rho_{v} v_{t-1}+\varepsilon_{t}^{v}
$$

where $\rho_{v} \in[0,1)$ and $\left\{\varepsilon_{t}^{v}\right\}$ is a zero mean white noise process. $\gamma$ denotes the interest rate smoothing coefficient. The higher the interest rate smoothing parameter, the lower the response of nominal interest rate to output gap and inflation. Coefficients $\phi_{\pi}$ and $\phi_{y}$ are set by monetary authorities and can be thought as the responsiveness of nominal interest rate to inflation and output gap respectively. Note that, a positive realization of $\varepsilon_{t}^{v}$ results in an increase in the nominal interest rate and hence can be interpreted as a contractionary monetary policy shock. Conversely, a negative realization of $\varepsilon_{t}^{v}$ would lead to a decrease in the nominal interest rate and can be interpreted as an expansionary monetary policy.

\section{Equilibrium}

Goods market clearing requires quantity produced matches quantity demanded. Since consumption is the only source of demand for goods, given that $\mathrm{Y}_{\mathrm{t}}=\left(\int_{0}^{1} \mathrm{Y}_{\mathrm{t}}(\mathrm{i})^{1-\frac{1}{\epsilon}} \mathrm{di}\right)^{\frac{\epsilon}{\epsilon-1}}$ total production equals total consumption, the dynamics of the model can be characterized by the first-order conditions obtained from the optimization problems and the market clearing conditions. Firstly, the model is written in terms of stationary variables and is solved for the deterministic steady state. Then, the model is log-linearized around this non-stochastic steady-state. The resulting log-linear equations are summarized in Table 1.

A closed economy New Keynesian DSGE model's building blocks consist of a forwardlooking dynamic IS equation, a New Keynesian Phillips curve which constitutes the non-policy block and the model is closed by policy block of a Taylor-type monetary policy rule. For this model, the corresponding equations can be found in the first three rows of Table 1 respectively.

\footnotetext{
${ }^{4}$ Originally, Taylor rule is written in terms of $\hat{y}_{t}$, where $\hat{y}_{t}=y_{t}-y$ is the deviation of output from its steady state value. However, after some manipulation, we may express the equation in terms of output gap. For further information, one can refer to Gali(2015).
} 
Table 1 Log-linearized model equations

Dynamic IS Equation

New Keynesian Phillips Curve

Taylor rule

Evolution of natural rate of interest

Consumption equation

Price level

Marginal cost

Optimal price level

Aggregate employment

Production function

Ad-hoc money demand

Output gap

Natural level of output

Market Clearing Conditions

$$
\begin{aligned}
\tilde{y}_{t} & =-\frac{1}{\sigma}\left(i_{t}-E_{t}\left\{\pi_{t+1}\right\}-r_{t}^{n}\right)+E_{t}\left\{\tilde{y}_{t+1}\right\} \\
\pi_{t} & =\beta E_{t}\left\{\pi_{t+1}\right\}+\kappa \tilde{y}_{t} \\
i_{t} & =\rho+\gamma i_{t-1}+\phi_{\pi} \pi_{t}+\phi_{y} \tilde{y}_{t}+v_{t} \\
r_{t}^{n} & =\rho+\sigma \psi_{y a}^{n} E_{t}\left\{\Delta a_{t+1}\right\} \\
c_{t} & =E_{t}\left\langle c_{t+1}\right\rangle-\frac{1}{\sigma}\left(i_{t}-E_{t}\left\langle\pi_{t+1}\right\rangle-\rho\right) \\
& \quad+\frac{1}{\sigma}\left(1-\rho_{z}\right) z_{t}
\end{aligned}
$$

$p_{t}=\theta p_{t-1}+(1-\theta) p_{t}^{*}$

$\psi_{t}=w_{t}-\left(a_{t}-\alpha n_{t}+\log (1-\alpha)\right)$

$p_{t}^{*}=\mu+(1-\beta \theta) \sum_{k=0}^{\infty}(\beta \theta)^{k} E_{t}\left\{\psi_{t+k \mid t}\right\}$

$n_{t}=\frac{1}{1-\alpha}\left(y_{t}-a_{t}\right)$

$y_{t}=a_{t}+(1-\alpha) n_{t}$

$m_{t}=\pi_{t}+\tilde{y}_{t}-\eta i_{t}$

$\tilde{y}_{t}=y_{t}-y_{t}^{n}$

$y_{t}^{n}=\psi_{y a}^{n} a$

Goods market clearing

$$
Y_{t}=C_{t}
$$

\section{Shocks}

\begin{tabular}{ll}
\hline Technology shock & $a_{t}=\rho_{a} a_{t-1}+\varepsilon_{t}^{a}$ \\
Monetary policy shock & $v_{t}=\rho_{v} v_{t-1}+\varepsilon_{t}^{v}$ \\
Demand shock & $z_{t}=\rho_{z} z_{t-1}+\varepsilon_{t}^{z}$ \\
\hline
\end{tabular}

All variables are expressed in log-deviations from steady state.

\section{Calibration}

This section gives some informative results based on a calibrated version of the analyzed model economy. Some of the calibrated parameters in Table 2 are obtained from steady-state values and the remaining parameters are borrowed from the literature. The households' discount parameter $(\beta)$ is set at 0.9928 , which implies an annual real interest rate of $3 \%$ as many other studies conducted for the Turkish economy (Alp and Elekdağ, 2011; Çebi, 2012; Yüksel,2013). The capital share in production $(\alpha)$ is set to 
0.3 . The risk-aversion parameter is chosen as 3 , which means an intertemporal elasticity of substitution $(\sigma)$ of 0.5 which is in line with the existing literature (Çebi, 2012; Bari, 2016). The semi-elasticity of money demand $(\eta)$, the inverse of Frisch labor elasticity $(\varphi)$, and the price elasticity of demand $(\epsilon)$ are set 4,5 and, 9, respectively, as in Gali (2015). In addition, the Calvo $(\theta)$ parameter that measures the degree of price stickiness is set to 0.5 , which implies that an average duration of price is two-quarters, following the Turkish literature (Alp and Elekdağ, 2011; Çebi, 2011; Bari, 2016). Regarding the monetary policy parameters, Taylor rule coefficients leading the response to inflation and output are set to 1.5 and 0.25 , respectively as in Alp and Elekdağ (2011) and Bari (2016).Finally, the interest rate smoothing parameter $(\gamma)$ is calibrated as 0.70 , following the Turkish economy literature (Alp and Elekdağ (2011), Yüksel (2013) and Bari (2016)). Although Gali (2015) was calibrated for US economy, the parameters calibrated following Gali (2015) are highly compatible for the Turkish economy.

Table 2 Calibrated Parameters

\begin{tabular}{cll}
\hline Parameter & Description & Calibrated Value \\
\hline$\beta$ & Household's discount factor & 0.9928 \\
$\alpha$ & Capital share in production & 0.3 \\
$\epsilon$ & Demand elasticity & 9 \\
$\sigma$ & Intertemporal elasticity of substitution & 3 \\
$\varphi$ & Frisch labor supply elasticity & 5 \\
$\eta$ & Semi-elasticity of money demand & 4 \\
$\theta$ & Calvo parameter & 0.5 \\
$\rho_{z}$ & Autocorrelation demand shock & 0.5 \\
$\rho_{a}$ & Autocorrelation technology shock & 0.9 \\
$\rho_{v}$ & Autocorrelation monetary policy shock & 0.5 \\
$\phi_{\pi}$ & Inflation feedback Taylor rule & 1.5 \\
$\phi_{y}$ & Output feedback Taylor rule & 0.25 \\
$\gamma$ & Interest rate smoothing parameter & 0.70 \\
\hline
\end{tabular}

\section{Counterfactual Simulations}

Our aim is to investigate the effects of different monetary policy configurations on social welfare. The method we will use to do this will be to apply counterfactual simulations by assigning different values to inflation and output gap coefficients in the Taylor rule. In other words, the performance of alternative monetary policy rules that react to inflation and output gap stabilization differently will be compared. Such an assessment requires a quantitative criterion. In line with the majority of the existing literature, we follow the seminal work of Rotemberg and Woodford (1999). As a basis for comparison, a second order approximation to representative consumer's loss of utility as a conse- 
quence of deviations from the efficient allocation is applied. This approximation yields the following welfare loss function:

$$
W=\frac{1}{2} E_{0} \sum_{t=0}^{\infty} \beta^{t}\left[\left(\sigma+\frac{\varphi+\alpha}{1-\alpha}\right) \tilde{y}_{t}^{2}+\frac{\epsilon}{\lambda} \pi_{t}^{2}\right]
$$

where losses are expressed in terms of the equivalent permanent consumption decline, measured as a fraction of steady-state consumption. Thus, average welfare loss per period can be obtained by a linear combination of inflation variance and output gap variance:

$$
L=\frac{1}{2}\left[\left(\sigma+\frac{\varphi+\alpha}{1-\alpha}\right) \operatorname{var}\left(\tilde{y}_{t}\right)+\frac{\epsilon}{\lambda} \operatorname{var}\left(\pi_{t}\right)\right] 5
$$

Now, given the policy rule and calibration of model's parameters, the variance of inflation and output gap and associated welfare loss with respect to optimal allocation can be determined.

Our analysis will focus on both technology and demand shocks. These two shocks are analyzed separately in order to have a clear understanding of the transmission mechanism of each shock and conduct of monetary policy. We specify that the parameters in the above loss function vary a grid of values with each combination of values representing a different Taylor rule. For the purpose of reporting, we determine a limited space of parameter values - the response to inflation ranges between 0 and 5 and the response to output gap changes from 0 to 2 . It is important to emphasize that the objective here is not to explain the quantitative recipe on what the optimal coefficients are. Instead, we intend to gain qualitative explanations on whether these parameters may improve social welfare in a basic New Keynesian model. On the other hand, for each alternative scenario of the rule obtained in this paper, we simulate the model and calculate the asymptotic variance of output, inflation, and output gap and welfare loss.

Table 3 reports the standard deviation of output, output gap and inflation for different configurations of Taylor rule coefficients $\phi_{\pi}$ and $\phi_{y}$ and associated welfare loss resulting from the deviations from the efficient allocation, expressed as a percentage of steady state consumption. ${ }^{6}$ The magnitude of an expansionary monetary policy shock is equal to 25 basis points increase in $\varepsilon_{t}^{v}$ and it is a unit shock (variance of $\varepsilon_{t}^{v}$ equals 1 ). This scenario constitutes our benchmark case. Effects of technology and demand shock are examined separately. Each column represents a different Taylor rule. The weight attributed to output is in ascending order from left to right. Rules in the first and second columns do not respond to output fluctuations and especially second rule exhibits a very aggressive anti-inflation stance. The third rule is the original Taylor rule proposed by Taylor (1993). In the third, fourth and fifth rules weight attached to inflation stabiliza-

\footnotetext{
${ }^{5}$ When the coefficients are substituted for the calibration values of corresponding parameters, the form the loss function takes is as follows : $L=5.28 \operatorname{var}\left(\tilde{y}_{t}\right)+1.84 \operatorname{var}\left(\pi_{t}\right)$

${ }^{6}$ Gali(2015)
} 
tion is kept constant to observe the impacts of different configurations of output coefficient. The fifth rule presents a strong output stabilization intention.

Table 3 Evaluation of Alternative Taylor Rules

\begin{tabular}{|c|lllll|lllll|}
\hline & \multicolumn{5}{|c|}{ Technology Shock } & \multicolumn{5}{c|}{ Demand Shock } \\
\hline $\boldsymbol{\phi}_{\boldsymbol{\pi}}$ & 1.500 & 5 & 1.500 & 1.500 & 1.500 & 1.500 & 5 & 1.500 & 1.500 & 1.500 \\
$\boldsymbol{\phi}_{\boldsymbol{y}}$ & 0 & 0 & 0.125 & 0.250 & 1 & 0 & 0 & 0.125 & 0.250 & 1 \\
\hline $\boldsymbol{\sigma}(\boldsymbol{y})$ & 1.819 & 1.846 & 1.796 & 1.774 & 1.658 & 0.122 & 0.062 & 0.118 & 0.115 & 0.096 \\
$\boldsymbol{\sigma}(\widetilde{\boldsymbol{y}})$ & 0.063 & 0.024 & 0.086 & 0.108 & 0.230 & 0.122 & 0.062 & 0.118 & 0.115 & 0.096 \\
$\boldsymbol{\sigma}(\boldsymbol{\pi})$ & 0.162 & 0.048 & 0.340 & 0.519 & 1.521 & 0.147 & 0.066 & 0.140 & 0.134 & 0.107 \\
$\boldsymbol{L}$ & 0.040 & 0.006 & 0.077 & 0.125 & 0.594 & 0.151 & 0.038 & 0.141 & 0.132 & 0.093 \\
\hline
\end{tabular}

Table 3 indicates that in the case of a technology shock, volatility of output gap and inflation are in the same direction where the volatility of output is in opposite direction. This can be interpreted as a trade-off between stabilization of output and stabilization of inflation and output gap. As the weight attributed to output stabilization increases ( $\phi_{y}$ increases), volatility of output tends to decline but volatility of inflation and hence the welfare loss rises from 0.040 to $0.077,0.125$ and finally to 0.594 as $\phi_{y}$ equals $0,0.125,0.25$ and, 1 , respectively. On the other hand, if output stabilization intention is kept constant to be zero and anti-inflationary stance becomes stronger, the volatility of output increases but volatility of inflation and output gap and welfare loss reduce. As a result, it can be concluded that when the technology shock is the source of fluctuations, welfare loss is minimized in the case where monetary policy does not react to output stabilization and responds very aggressively to inflation $\left(\phi_{\pi}=5, \phi_{y}=0\right) .{ }^{7}$

It can be observed that when we deal with a demand shock, the tradeoff we have encountered in the case of a technology shock vanishes. The volatility of all variables and welfare loss tends to move in the same direction. An increase in the responsiveness of monetary policy to stabilize output leads to a decline in the welfare loss and volatility of output, output gap and inflation. Also, it can be noted that in the case of a demand shock, output gap and output stabilization is equivalent in the sense that the natural level of output remains constant. Contrary to the results we obtained in technology shock, increasing the responsiveness of monetary policy to both inflation and output stabilization leads to a reduction in welfare loss and volatility of output, output gap and inflation. ${ }^{8}$

\footnotetext{
${ }^{7} \mathrm{We}$ checked the robustness of the findings by incorporating an interest rate smoothing parameter into the Taylor rule. Modifying the interest rate smoothing parameter from 0.7 to 0.9 proved to generate only gradual differences in values. The patterns seem robust under different calibrations of interest rate smoothing parameter.

${ }^{8}$ We also applied a sensitivity analysis by changing the magnitude of the shocks. Results indicate that our findings are robust under different magnitudes of shocks. Although the magnitudes of the
} 


\section{Loss Function with Varying Output Gap Sensitivity}

In the literature, it is a standard procedure to minimize the loss function of the central bank to quantitatively measure the social welfare loss. In the previous section, the coefficients of the loss function are fixed as in Gali (2015). The policy analysis we conduct is very sensitive to the specification of the loss function. In this section, the welfare effects of different Taylor rules will be compared under different loss function specifications. Firstly, the inflation coefficient is assumed to be $2.8^{9}$ and only the coefficient in front of the output gap will be allowed to change in the range 0-10. The resulting loss function is as follows:

$$
L=\alpha_{\widetilde{y}} \operatorname{var}\left(\tilde{y}_{t}\right)+2.8 \operatorname{var}\left(\pi_{t}\right)
$$

Figure 2: Welfare loss under alternative Taylor rules with varying $\alpha$; Technology and demand shocks

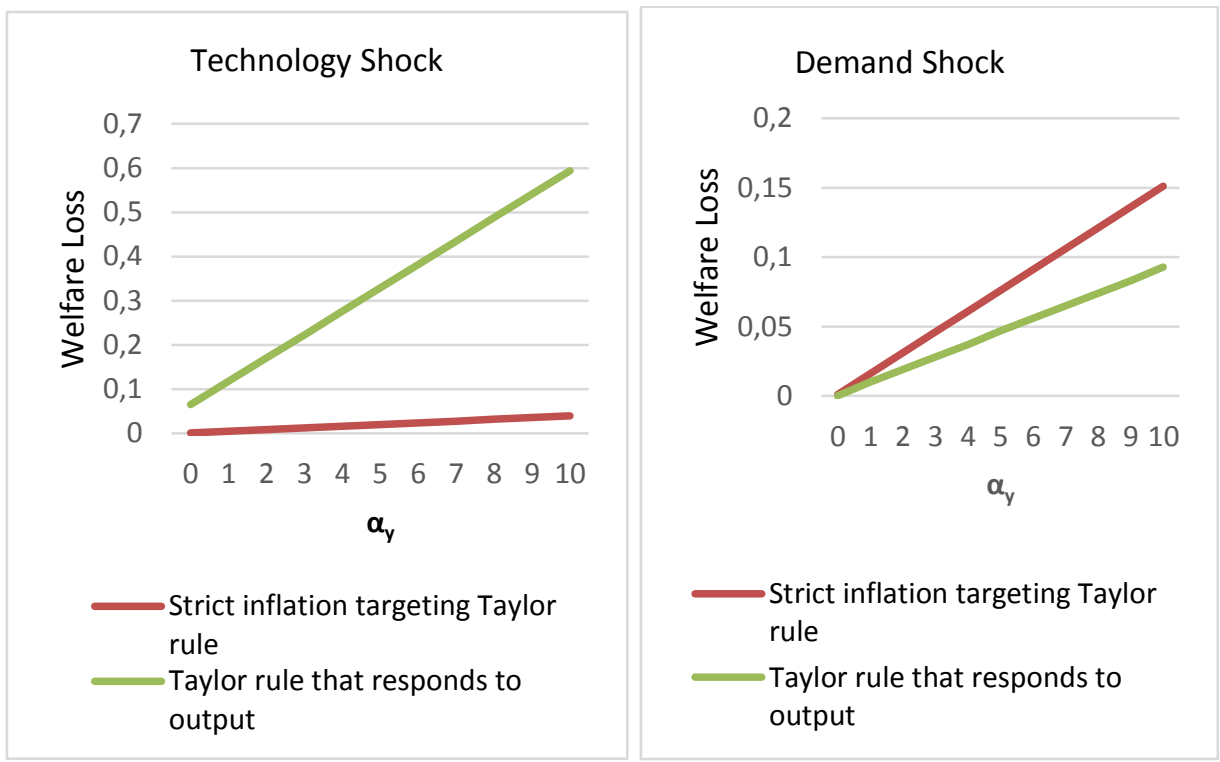

Figure 2 shows the how changing the alpha parameter varies the social welfare loss under two different Taylor rules: one marked with red color denotes strict inflation targeting rule $\left(\phi_{y}=0, \phi_{\pi}=1.5\right)$ and the blue one indicates the rule that responds also to output stabilization $\left(\phi_{y}=1, \phi_{\pi}=1.5\right)$.The $\mathrm{x}$-axis presents the output weighting parameter $\left(\alpha_{\widetilde{y}}\right)$, and y-axis reports the value of the loss attainable by the central bank.

welfare and output, output gap, and inflation volatilities differ, the conclusions we derived remain unchanged.

${ }^{9}$ This value is calculated from the computation of coefficient in front of inflation variance in equation (12). 
Consistent with the previous findings, under technology shock, the loss minimizing strategy of the Central Bank is strict inflation targeting with no response to output fluctuations. For each value of $\alpha_{\widetilde{y}}$, practicing an alternative Taylor rule that responds to output fluctuations results in significant welfare losses. Furthermore, the volatility of loss function values is much smoother under strict inflation targeting rule.

Regarding the demand shock case, contrary to the case of technology shock, the central bank's response to output also draws welfare loss lower for each $\alpha_{\widetilde{y}}$ value. In other words, the loss minimizing strategy incorporates responding to output fluctuations along with inflation stabilization. Another important finding is that the loss function volatility is significantly higher with Taylor rule that does not respond to output fluctuations in case of a demand shock. The loss function values obtained from the different Taylor

rules $\left[\left(\phi_{y}=0.125, \phi_{\pi}=1.5\right),\left(\phi_{y}=0.25, \phi_{\pi}=1.5\right),\left(\phi_{y}=0, \phi_{\pi}=5\right)\right]$ are also calculated but not reported here. Under all variations, findings are in line with the benchmark scenario.

\section{Loss Function with Varying Output Gap and Inflation Sensitivity}

In this section, the loss function has been modified in such a way that the inflation coefficients are allowed to change in the range 0-2 while output coefficients have a variation between 0 and 10. The corresponding loss function can be found as follows:

$$
L=\alpha_{\widetilde{y}} \operatorname{var}\left(\tilde{y}_{t}\right)+\alpha_{\pi} \operatorname{var}\left(\pi_{t}\right)
$$

For the sake of clarity, the values that $\alpha_{\widetilde{y}}$ and $\alpha_{\pi}$ can take are limited to $[0,2,5,10]$ and $[0.5,1,1.5,2]$ respectively. Table 4 reports the welfare loss values with associated $\alpha_{\widetilde{y}}$ and $\alpha_{\pi}$ configurations under three alternative Taylor rules.

An apparent finding is that under the rule with a very strong anti-inflationary stance but no response to the output $\left(\phi_{y}=0, \phi_{\pi}=5\right)$, in the case of a technology shock, the maximum value the loss function attains is 0.006 . Furthermore, varying the parameters in the loss function does not have a significant effect on welfare loss in the case of a demand shock, too. In other words, in the presence of a very strict inflation targeting scheme, loss function specification does not have a remarkable impact. Another expected finding is that the change in the output parameter in the Taylor rule does not have a social welfare effect if the loss function output gap coefficient is 0 .

Keeping the output weight constant and varying inflation weight in loss function results in very marginal rises in welfare loss, if there exists any, in the case of a demand shock. Overall, it can be concluded that the technology shock is relatively more sensitive to the alterations in the coefficients of the loss function. In line with our benchmark scenario, it is shown that in the case of a technology shock, an attempt to stabilize output results with a loss of welfare. And again, similar to the benchmark scenario, in the case of a demand shock, an increase in the motive of output stabilization reduces the associated welfare loss. To sum up, it can be interpreted that key findings under the benchmark scenario are robust against different loss function configurations. 
Table 4 Welfare loss under alternative Taylor rules with varying $\alpha_{\tilde{y}}$ and $\alpha_{\pi}$; Technology and demand shocks

\begin{tabular}{|c|c|cc|cc|cc|}
\hline \multicolumn{2}{|c|}{} & \multicolumn{2}{|c|}{$\begin{array}{l}\phi_{\pi}=1.5 \text { and } \phi_{\mathrm{y}} \\
=0\end{array}$} & \multicolumn{2}{|c|}{$\phi_{\pi}=1.5$ and $\phi_{\mathrm{y}}=1$} & \multicolumn{2}{|c|}{$\phi_{\pi}=5$ and $\phi_{\mathrm{y}}=0$} \\
\hline $\begin{array}{c}\text { Output } \\
\text { weight }\end{array}$ & $\begin{array}{c}\text { Inflation } \\
\text { weight }\end{array}$ & $\begin{array}{c}\text { Loss } \\
\text { under } \\
\text { Tech- } \\
\text { nology } \\
\text { Shock }\end{array}$ & $\begin{array}{c}\text { Loss } \\
\text { under } \\
\text { Demand } \\
\text { Shock }\end{array}$ & $\begin{array}{c}\text { Loss under } \\
\text { Technology } \\
\text { Shock }\end{array}$ & $\begin{array}{c}\text { Loss } \\
\text { under } \\
\text { Demand } \\
\text { Shock }\end{array}$ & $\begin{array}{c}\text { Loss } \\
\text { Loss under } \\
\text { Technology } \\
\text { Shock }\end{array}$ & $\begin{array}{c}\text { Inder } \\
\text { Demand } \\
\text { Shock }\end{array}$ \\
\hline 0 & 0.5 & 0 & 0 & 0 & 0 & 0.012 & 0 \\
\hline 0 & 1 & 0 & 0 & 0.023 & 0 & 0 & 0 \\
\hline 0 & 1.5 & 0 & 0 & 0.035 & 0 & 0 & 0 \\
\hline 0 & 2 & 0.001 & 0 & 0.046 & 0 & 0 & 0 \\
\hline 2 & 0.5 & 0.008 & 0.030 & 0.117 & 0.019 & 0.001 & 0.008 \\
\hline 2 & 1 & 0.008 & 0.030 & 0.129 & 0.019 & 0.001 & 0.008 \\
\hline 2 & 1.5 & 0.008 & 0.030 & 0.141 & 0.019 & 0.001 & 0.008 \\
\hline 2 & 2 & 0.008 & 0.030 & 0.152 & 0.019 & 0.001 & 0.008 \\
\hline 5 & 0.5 & 0.020 & 0.075 & 0.276 & 0.046 & 0.003 & 0.019 \\
\hline 5 & 1 & 0.020 & 0.075 & 0.288 & 0.046 & 0.003 & 0.019 \\
\hline 5 & 1.5 & 0.020 & 0.075 & 0.299 & 0.046 & 0.003 & 0.019 \\
\hline 5 & 2 & 0.020 & 0.075 & 0.311 & 0.046 & 0.003 & 0.019 \\
\hline 10 & 0.5 & 0.039 & 0.150 & 0.541 & 0.092 & 0.006 & 0.038 \\
\hline 10 & 1 & 0.040 & 0.150 & 0.552 & 0.092 & 0.006 & 0.038 \\
\hline 10 & 1.5 & 0.040 & 0.150 & 0.564 & 0.093 & 0.006 & 0.038 \\
\hline & 2 & 0.040 & 0.150 & 0.575 & 0.093 & 0.006 & 0.038 \\
\hline
\end{tabular}

\section{Conclusion}

This paper studies the welfare consequences of alternative monetary policy implementations in a New Keynesian DSGE model borrowed from Gali (2015). The aim is to evaluate different monetary policy configurations for an economy that is subject to technology and demand shocks. The Central Bank is assumed to follow a Taylor-type interest rate rule reinforced with the interest rate smoothing parameter. Firstly, welfare effects of alternative Taylor rules are examined under a loss function following Woodford (1999) and Gali (2015). The study makes an important contribution to the existing literature by analyzing how different coefficients of Taylor rule perform in a model with different configurations of loss function in the context of a DSGE model for Turkey.

Our findings indicate that a strong reaction to inflation in the Taylor rule provides lower welfare loss if the fluctuations of the economy originate from technology shocks. Moreover, the higher the importance given to output stabilization, the higher the welfare loss the central bank faces. However, this sort of variation of loss minimization does not 
appear in the presence of demand shocks even if the relative importance of output stabilization increases in the context of Taylor rule. From the policy perspective, these findings reveal that welfare losses are likely to be smaller if the monetary authority pursues a strict price stability instead of output stabilization. However, a welfare improvement may be possible by attempting to stabilize output in the case of a demand shock.

Since the findings are extremely sensitive to the loss function specification, we allowed the coefficients of the loss function to vary while testing for particular Taylor rule configurations. Our findings indicate that both in the case with varying output sensitivity and in the case of varying inflation and output sensitivity, results are compatible with our benchmark scenario. In other words, our findings are robust under different loss function configurations.

Disclosure statement: No potential conflict of interest was reported by the authors.

\section{REFERENCES}

AKLAN, A. N, and NARGELECEKENLER, M. (2008). Taylor Rule in Practice: Evidence from Turkey. International Advances in Economic Research, Vol.14, No:2, ss:156-166.

ADOLFSON, M., LASEEN, S., LINDE, and J., SVENSSON. (2014). Monetary Policy Trade-offs in an Estimated DSGE Model. Journal of Economic Dynamics and Control, 42, p. 33-49. DOI: $\underline{10.1016 / j . j e d c .2014 .02 .012}$

ALP, H., ELEKDAĞ, S. (2011). The Role of Monetary Policy in Turkey during the Global Financial Crisis. IMF Working Paper, 11/150.

BARI, B., SIKLAR, İ. (2016). The Analysis of Monetary Policy in the Inflation Targeting Regime: An Estimated DSGE Model for Turkey. Anadolu University Journal of Social Sciences, p. 47-69.

BERUMENT, H., and TAŞÇI, H. (2004). Monetary policy Rules in Practice: Evidence from Turkey. International Journal of Finance, 9 (2004), pp: 33-38. DOI: $\underline{10.1002 / i j f e .219}$

BOUDA, M. (2015). The New Keynesian DSGE Model and Alternative Monetary Policy Rules in the Czech Republic. Acta Oeconomica Pragensia, 1, 2014.

BULUT, Ü. (2017). Monetary Policy and Asset Prices in the Period Following the Global Crisis: The Case of Turkey. Journal of Economics and Administrative Sciences, Eskişehir Osmangazi University, Vol.12, pp.13-30.

CALVO, G.A. (1983). Staggered Prices in a Utility-Maximizing Framework. Journal of Monetary Economics, Vol.12, pp. 383-398. DOI: 10.1016/0304-3932(83)90060-0

CHRISTIANO, J. L., EICHENBAUM, M., and EVANS, C.L. (2005). Nominal Rigidities and the Dynamic Effects of a Shock to Monetary Policy.Journal of Political Economy, Vol. 113, No.1, p.1-45 
CLARIDA, R. H. (2014). Monetary Policy in Open Economies: Practical Perspectives for Pragmatic Central Bankers, Journal of Economics Dynamics and Control, Vol. 49. p. 21-30. DOI: 10.1016/j.jedc.2014.09.036

CURDIA, V., and FINOCCHIARO, D. (2013). Monetary Regime Change and Business Cycles. Journal of Economic Dynamics and Control, Vol. 37, pp. 756-773. DOI: $\underline{10.1016 / j . j e d c .2012 .12 .004}$

ÇEBİ, C. (2012). The Interaction between Monetary and Fiscal Policies in Turkey: An Estimated New Keynesian DSGE Model. Economic Modelling, Vol. 29, p. 1258-1267. DOI: $10.1016 /$ j.econmod.2012.04.014

GALI, J. (2015) Monetary Policy, Inflation, and the Business Cycle: An Introduction to the New Keynesian Framework and Its Applications, Second Edition, Princeton University Press.

GAMBACORTA, L., and SIGNORETTI, F. M. (2014). Should monetary policy lean against the wind? An analysis based on a DSGE model with banking. Journal of Economic Dynamics and Control, Vol. 43, pp. 146-174. DOI: 10.1016/j.jedc.2014.01.016

GÜNEY, P. O. (2016). Does the Central Bank Directly Respond to Output and Inflation Uncertainties in Turkey? Central Bank Review. Vol. 16, p. 53-57.

GÜRKAYNAK, R., KANTUR, Z., TAŞ, M. A., and YILDIRIM-KARAMAN, S. (2015). Monetary Policy in Turkey after Central Bank Independence. İktisat İşletme ve Finans, Vol 30 (356), November 2015. DOI: 10.1016/j.jedc.2014.01.016

KARA, H.A (2006). Turkish Experience with Implicit Inflation Targeting. The Central Bank of the Republic of Turkey, Research and Monetary Policy Department, Working Paper, No: 6/3.

ÖZATAY, F. (2011). The New Monetary Policy of the Central Bank: Two TargetsThree Intermediate Targets-Three Tools, Economics, Business, and Finance. Vol. 26, Issue 302, pp. 27-43. DOI: 10.3848/iif.2011.302.2743

ÖZÇELEBI, O., YILDIRIM, N. and KANSU, A. (2014). Possible Effects of Domestic and Foreign Factors on Monetary Policy Implementation in Turkey: A DSGE-VAR Approach. Economic Research, Vol. 27, Issue 1, pp. 590-606. DOI: $\underline{10.1080 / 1331677 X .2014 .974339}$

PATRA, M. D., KHUNDRAKPAM, J. K., and GANGADARAN, S. (2017). The Quest for Optimal Monetary Policy Rules in India. Journal of Policy Modelling, Vol. 39, pp. 349-370. DOI: 10.1016/j.jpolmod.2017.01.006

PEHLIVANOGLU, F. (2014). The Estimation of Taylor Type Interest Rate Reaction's Function in the Frame of Optimal Monetary Policy: The Case of Turkey. The Journal of Knowledge Economy and Knowledge Management, Vol. 9, pp.116-126.

ROTEMBERG, J. J. and WOODFORD M. (1999) The Cyclical Behavior of Prices and Costs. NBER Working Paper, No. 6909. 
SEKMEN, T. and ŞIKLAR, İ. (2016). Monetary Policy and Macroprudential Policies: An Estimated DSGE Model of the Turkey, Anadolu University Journal of Social Sciences, Vol. 16, No. 4, p. 47-69.

SMETS, F. and WOUTERS, R. (2007). Shocks and Frictions in US Business Cycles: A Bayesian DSGE Approach. American Economic Review, Vol. 97, No. 3, June 2007, p. 586-606. DOI: $\underline{10.1257 / \text { aer.97.3.586 }}$

USLU, Ç.L., and ÖZÇAM, A. (2014). A Modified Taylor Rule for The Central Bank of Turkey (CBRT): 2003-2012. KSÜ, Journal of Faculty of Economics and Administrative Science, Vol. 4, Issue 1, pp. 223-245.

YÜKSEL, C. (2013). Role of Investment Shocks in Explaining Business Cycles in Turkey. The Central Bank of the Republic of Turkey, Working Paper, No: 13/12.

YÜKSEL, E., METIN-ÖZCAN, K. and HATIPOĞLU, O. (2013). A Survey on TimeVarying Parameter Taylor Rule: A Model Modified with Interest Rate Pass-Through. Economic Systems, Vol. 37, pp. 122-134. DOI: 10.1016/j.ecosys.2012.08.002

WOODFORD, M. (1999). Optimal Monetary Policy Inertia, NBER Working Paper Series, 7261. 